\title{
Assessment of Anopheles salivary antigens as individual exposure biomarkers to species-specific malaria vector bites
}

Zakia M I Ali ${ }^{1 \dagger}$, Mahfoud Bakli, ${ }^{1,2+}$, Albin Fontaine ${ }^{1}$, Nawal Bakkali ${ }^{1}$, Vinh Vu Hai ${ }^{1,2}$, Stephane Audebert ${ }^{3}$, Yvan Boublik ${ }^{4}$, Frederic Pagès ${ }^{5,6}$, Franck Remoué ${ }^{7}$, Christophe Rogier ${ }^{1,8}$, Christophe Fraisier ${ }^{1}$ and Lionel Almeras ${ }^{1,2^{*}}$

\begin{abstract}
Background: Malaria transmission occurs during the blood feeding of infected anopheline mosquitoes concomitant with a saliva injection into the vertebrate host. In sub-Saharan Africa, most malaria transmission is due to Anopheles funestus s.s and to Anopheles gambiae s.l. (mainly Anopheles gambiae s.s. and Anopheles arabiensis). Several studies have demonstrated that the immune response against salivary antigens could be used to evaluate individual exposure to mosquito bites. The aim of this study was to assess the use of secreted salivary proteins as specific biomarkers of exposure to An. gambiae and/or An. funestus bites.
\end{abstract}

Methods: For this purpose, salivary gland proteins 6 (SG6) and 5'nucleotidases (5'nuc) from An. gambiae (gSG6 and g-5'nuc) and An. funestus (fSG6 and f-5'nuc) were selected and produced in recombinant form. The specificity of the $\lg G$ response against these salivary proteins was tested using an ELISA with sera from individuals living in three Senegalese villages (NDiop, $n=50$; Dielmo, $n=38$; and Diama, $n=46$ ) that had been exposed to distinct densities and proportions of the Anopheles species. Individuals who had not been exposed to these tropical mosquitoes were used as controls (Marseille, $\mathrm{n}=45$ ).

Results: The IgG responses against SG6 recombinant proteins from these two Anopheles species and against g-5'nucleotidase from An. gambiae, were significantly higher in Senegalese individuals compared with controls who were not exposed to specific Anopheles species. Conversely, an association was observed between the level of An. funestus exposure and the serological immune response levels against the $f-5$ 'nucleotidase protein.

Conclusion: This study revealed an Anopheles salivary antigenic protein that could be considered to be a promising antigenic marker to distinguish malaria vector exposure at the species level. The epidemiological interest of such species-specific antigenic markers is discussed.

Keywords: Anopheles gambiae, Anopheles funestus, Antigenic salivary proteins, SG6, 5'nucleotidase, Exposure biomarkers, Epidemiology

\footnotetext{
* Correspondence: almerasl@imtssa.fr

${ }^{\dagger}$ Equal contributors

'Unité de recherche en biologie et épidémiologie parasitaires (URBEP) UMR63 - IFR48, Institut de Recherche Biomédicale des Armées (Armed forces biomedical research institute, IRBA), antenne Marseille, GSBdD de Marseille Aubagne, 111 avenue de la corse, BP 40026, Marseille cedex 02 13568, France

${ }^{2}$ Aix Marseille Université, Unité de Recherche en Maladies Infectieuses et Tropicales Emergentes (URMITE), UM63, CNRS 7278, IRD 198, Inserm 1095, WHO collaborative center for rickettsioses and other arthropod borne bacterial diseases, Faculté de Médecine, 27 bd Jean Moulin, Marseille cedex 5 13385, France

Full list of author information is available at the end of the article
}

\section{Background}

Malaria remains a major public health burden, affecting approximately 240 million individuals annually and causing more than 800,000 deaths, mainly in populations living in tropical and sub-tropical countries in sub-Saharan Africa [1]. To date, the absence of a licensed malaria vaccine [2-4] and the spread of parasite resistance against malaria treatment [5] necessitate strengthening the control of malaria exposure by avoiding host/vector contact. Thus, several strategies could be used to protect individuals from mosquito bites, either by using personal anti-

\section{() Biomed Central}

(c) 2012 Ali et al.; licensee BioMed Central Ltd. This is an Open Access article distributed under the terms of the Creative Commons Attribution License (http://creativecommons.org/licenses/by/2.0), which permits unrestricted use, distribution, and reproduction in any medium, provided the original work is properly cited. 
vectorial devices, like impregnated bed nets, repellents, and long-sleeved clothes [6], or by controlling vector populations at both the adult and larval stages $[7,8]$. The effectiveness of these anti-vectorial devices is generally evaluated with parasitological and entomological methods [9-11]. Although these methods have demonstrated their capacity to estimate human exposure to malaria vectors and Anopheles densities, these tools lack important logistics and present limited efficiency in the context of lowlevel exposure to Anopheles bites. In addition, they are not designed for the assessment of the heterogeneity of mosquito exposure at the individual level [9]. Therefore, the development of new indicators and methods to evaluate the effectiveness of anti-vectorial strategies at the individual level is necessary.

Mosquito salivary proteins injected into the host during blood feeding play a dual role by counteracting homeostasis and modulating the vertebrate immune response [12]. In addition to their role in the blood meal, some salivary proteins presenting immunogenic properties could elicit an antibody response by their host. This immune response, initially described in allergic individuals [13], has been proposed as a marker of exposure to mosquito bites $[14,15]$. Thus far, several studies have demonstrated that the level of IgG immune responses against salivary antigens is associated with the level of individual exposure to mosquito bites, which may vary according to seasonal mosquito density $[15,16]$, transient exposure following travel in malaria-endemic areas [17] or following the introduction of anti-vectorial measures, such as the use of insecticide-treated nets [18]. However, the existence of homologous salivary protein sequences that are shared among different species from Culicidae requires the identification of specific antigenic proteins or peptides prior to developing any anti-saliva based immunological tools to assess individual exposure to different mosquito vectors $[9,19]$.

Among mosquito salivary proteins, the Anopheles gambiae salivary gland protein 6 (gSG6) was proposed as a potential candidate for the examination of specific malaria vector exposure markers [20]. This small protein, expressed specifically in the salivary glands of adult female mosquitoes, was selected based on its restrictive presence in species belonging to the subgenus Cellia, including major Afrotropical malaria vectors (e g, An. gambiae species complex, Anopheles funestus) [21], and its immune recognition by individuals exposed to Anopheles [17]. To limit production costs, Poinsignon and colleagues designed a gSG6-based peptide sequence (gSG6-P1) according to its predicted immunogenic properties [20]. The gSG6-P1 peptide was repeatedly reported to be a relevant An. gambiae-specific marker of exposure [20-23]. Moreover, the high level of amino-acid conservation between gSG6-P1 peptide sequences from An.gambiae and An. funestus indicate the potential of this peptide to be an indicator of exposure to both of these main vectors of Plasmodium falciparum in Africa [24]. Similar observations were obtained using recombinant forms of whole SG6 orthologs from An. gambiae and An. funestus [25,26], which could be attributed to the high level of identity among them (i.e., 80\%). More recently, it was reported that the level of IgG against gSG6 was positively linked to the risk of malaria pathogen transmission [27]. Thus, SG6 proteins are currently the best and uniquely relevant indicators of exposure to Afrotropical malaria vectors.

However, the identification of salivary antigenic candidates capable of discriminating individual exposure at the species level could improve the development of this type of immunological test by determining the anopheline fauna biting population. Effectively, together with An. funestus, mosquitoes from the An. gambiae s.l. (An. gambiae s.s. and Anopheles arabiensis) are the most common vectors of human malaria in sub-Saharan Africa [28]. These highly anthropophilic Anopheles species could geographically co-inhabit most sub-Saharan countries [29]. Malaria parasites can thus be transmitted by multiple and often sympatric vectors [30-32]. However, anopheline fauna could be spatially and temporally influenced by several factors, such as environmental conditions that could seasonally modify the anopheline species proportions and densities. During the dry season, the An. gambiae s.l. density is decreased for the benefit of An. funestus. The maintenance of malaria transmission at several sites could be attributed to the presence of An. funestus [33]. Thus, in addition to the use of salivary exposure markers to estimate the individual level of exposure to Afrotropical malaria vectors, the characterization of new species-specific anopheline salivary antigenic candidates could be useful for determining the predominant mosquito populations of a study area. Such information could be useful for the adaptation of vectorial control measures against specific mosquito populations or for the estimation of the risk of malaria transmission or persistence.

Thus, the aim of this study was to assess anopheline salivary proteins that could be used as species-specific exposure biomarkers to distinguish An. funestus exposure from An. gambiae s.l. exposure. First, SG6 salivary proteins from An. gambiae s.s. (gSG6) and An. funestus (fSG6) were produced in recombinant forms and evaluated on sera from individuals that were either un-exposed to Anopheles or exposed predominantly to An. funestus or An. gambiae s.l., to confirm that these salivary proteins could be used to detect a predominant exposure to either of these two mosquito species. In addition, recombinant forms of 5 'nucleotidase salivary proteins from An. gambiae s.s. (g-5'nuc) and An. funestus (f-5'nuc) were tested on the same sera to assess their potential as species-specific 
indicators of exposure. The specificity of the IgG response against these selected salivary proteins at the genus or species levels was analyzed by ELISA using sera from individuals living in three Senegalese villages (NDiop, $\mathrm{n}=50$; Dielmo, $\mathrm{n}=38$; and Diama, $\mathrm{n}=46$ ) exposed to distinct densities and proportions of the Anopheles species. Individuals that were not exposed to these tropical mosquitoes were used as controls (Marseille, $n=45$ ).

\section{Methods}

\section{Ethics statement}

The protocol ( $\left.\mathrm{N}^{\circ} 2006-\mathrm{A} 00581-50\right)$ was approved by the Marseille-2 Ethical Committee (France) and by the Senegal National Ethics Committee (Dakar, Senegal). The written informed consent of each participant was obtained at the beginning of the study, after a thorough explanation of its purpose.

Study sites, sera samples and entomological observations The study was conducted on two different populations: un-exposed people and people who were regularly exposed to An. gambiae s.l. and An. funestus bites. Forty-five serum samples from French adults living in Marseille $\left(43^{\circ} 17^{\prime} \mathrm{N}\right.$, $5^{\circ} 22^{\prime} \mathrm{E}$; mean age \pm standard deviation (SD): $40.73 \pm 12.02$, sampled in February 2007 [16]), who had never been in countries endemic for An. gambiae s.l. and An. funestus, were used as un-exposed negative controls. The exposed group consisted of 134 individuals living in the Senegalese villages of Diama $\left(16^{\circ} 13^{\prime} \mathrm{N}, 16^{\circ} 23^{\prime} \mathrm{W} ; \mathrm{n}=46\right.$, mean age \pm
SD: $17.96 \pm 11.58$, sampled between March and October 1994), Dielmo $\left(13^{\circ} 45^{\prime} \mathrm{N}, 16^{\circ} 25^{\prime} \mathrm{W} ; \mathrm{n}=38,28.38 \pm 21.26\right.$, sampled in March 1995) and Ndiop $\left(13^{\circ} 14^{\prime} \mathrm{N}, 16^{\circ} 23^{\prime} \mathrm{W}\right.$; $\mathrm{n}=50,25.87 \pm 18.34$, sampled between March and December 1995). These populations were exposed to high (Dielmo, approximately a 30.6 human biting rate (HBR), moderate (Ndiop, approximately a $3.9 \mathrm{HBR}$ ) and low (Diama, <1 HBR) Anopheles bite levels. Individuals living in Dielmo and Ndiop were predominantly exposed to An. funestus (approximately 66\%) and An. gambiae s.l. (approximately 95\%), respectively. Individuals living in Diama were predominantly exposed to other anopheline mosquito species (Anopheles pharoensis, approximately 87\%). Details regarding the entomological data are presented in Table 1 and show for each site the amount and the proportion of each anopheline species collected from the three months preceding blood sampling until the end of the blood sampling period. Concerning entomological measures, adult mosquitoes were collected monthly using human bait catches and the HBR, which is the number of mosquito bites per person per night, was calculated as the number of mosquitoes captured during the month divided by the number of person-nights. Additional data on the study site, including entomological and parasitological factors, have been previously reported [34-40].

\section{Protein expression and purification}

The coding sequences for the anopheline proteins gSG6 (gi|13537666), g-5'nucleotidase (gi|4582528), fSG6 (gi|

Table 1 Characteristics of density and exposure to Anopheles bites in each site according to entomological data

\begin{tabular}{|c|c|c|c|c|c|}
\hline Location & $\begin{array}{l}\text { Number of } \\
\text { Anopheles caught }\end{array}$ & $\begin{array}{l}\text { Percentage } \\
\text { composition }\end{array}$ & $\begin{array}{l}\text { HBR } \\
\text { (An./person/night) }\end{array}$ & $\begin{array}{l}\text { Collection } \\
\text { period }\end{array}$ & References \\
\hline Diama & 1,492 & & $<1$ & \multirow{6}{*}{$\begin{array}{l}\text { January '94 - } \\
\text { December '94 }\end{array}$} & \multirow[t]{6}{*}[37,38,39]{} \\
\hline An. gambiae s.l. & 17 & $1.1 \%$ & & & \\
\hline An. gambiae s.s. & n.d. & n.d. & & & \\
\hline An. arabiensis & n.d. & n.d. & & & \\
\hline An. funestus & 0 & $0.0 \%$ & & & \\
\hline Others Anophelines (86.9\% of An. pharoensis) & 1475 & $98.9 \%$ & & & \\
\hline Dielmo & 1,473 & & 30.6 & \multirow{6}{*}{$\begin{array}{l}\text { January '95 to } \\
\text {-march '95 }\end{array}$} & \multirow[t]{6}{*}{ [34] } \\
\hline An. gambiae s.l. & 494 & $33.5 \%$ & 10.3 & & \\
\hline An. gambiae s.s. & 13 & $0.9 \%$ & 0.3 & & \\
\hline An. arabiensis & 481 & $32.6 \%$ & 10.0 & & \\
\hline An. funestus & 978 & $66.4 \%$ & 20.3 & & \\
\hline Others Anophelines & 1 & $0.0 \%$ & 0.0 & & \\
\hline NDiop & 597 & & 3.9 & \multirow{6}{*}{$\begin{array}{l}\text { January '95 - } \\
\text {-December '95 }\end{array}$} & \multirow[t]{6}{*}[35,36]{} \\
\hline An. gambiae s.l. & 565 & $94.6 \%$ & 3.7 & & \\
\hline An. gambiae s.s. & 190 & $32 \%$ & 1.3 & & \\
\hline An. arabiensis & 373 & $63 \%$ & 2.5 & & \\
\hline An. funestus & 28 & $4.7 \%$ & 0.2 & & \\
\hline Others Anophelines & 4 & $0.7 \%$ & 0.0 & & \\
\hline
\end{tabular}

n.d.: not determined, HBR: human biting rate. 
114864550) and f-5'nucleotidase (gi|114864746) were retrieved from the National Center for Biotechnology Information (NCBI) database. The cDNAs of selected proteins were synthesized with a C-terminal His-tag and cloned into the baculovirus expression vector pFast Bac1 (Invitrogen, Cergy Pontoise, France) by Genecust (Gencust, Dudelange, Luxembourg). The fidelity of the cloned sequences was verified by DNA sequencing, using an ABI Prism 3100 analyzer (Applied Biosystems). Recombinant bacmid DNA was generated in the DH10Bac Escherichia coli strain (Invitrogen), using the Bac-to-Bac system and protocol (Invitrogen). Spodoptera frugiperda (Sf9) cells were transfected with the recombinant bacmid DNA using the Lipofectin transfection reagent (Invitrogen), according to the manufacturer's instructions. The structures of all the inserts were sequenced for authentic cloning (ABI Prism 3100 analyzer, Applied Biosystems). Confirmed clones were amplified in Spodoptera frugiperda (Sf9) cells in serum-free medium (Sf-900 II SFM, Gibco, Carlsbad, CA) to produce working viral stocks, which were titrated by a plaque assay and used for subsequent expression studies. For protein production, Sf9 cells were cultured at $28^{\circ} \mathrm{C}$ in $800 \mathrm{ml}$ of suspension culture $\left(1,3 \times 10^{6} \mathrm{Sf} 9\right.$ cells/ml), infected with a multiplicity of infection of 5 and harvested after three days by centrifugation at $500 \times \mathrm{g}$ for $15 \mathrm{~min}$ at $4^{\circ} \mathrm{C}$, washing in $\mathrm{PBS}$ and repeating centrifugation. All pellets were stored at $-80^{\circ} \mathrm{C}$ until use. The cell pellet was resuspended in lysis buffer (50 mM Tris, pH 7.9, $300 \mathrm{mM} \mathrm{NaCl}, 20 \mathrm{mM}$ imidazole, with proteolysis inhibitor P8849 (Sigma), and disrupted using an Emulsiflex C3 cell disruptor (Avestin, Mannheim, Germany). The cell lysate was clarified by centrifugation at 40,000 rpm for $45 \mathrm{~min}$ at $4^{\circ} \mathrm{C}$ (45 Tirotor, Beckman Coulter). The recombinant proteins were purified using HisTrap HP columns (AKTA purifier 10GEH, GE Healthcare, France). The fractions containing the Histagged recombinant proteins were selected by SDS-PAGE and pooled. To eliminate contaminant proteins, pooled fractions of each recombinant protein were then purified by gel filtration (superdex 75 26/60 column, GE Healthcare). The fractions containing recombinant proteins were identified by SDS-PAGE, pooled and dialyzed against a 40 $\mathrm{mM}$ Tris-HCl buffer ( $\mathrm{pH} 7.5)$. The protein concentration was measured using a Lowry DC Protein assay (Bio-Rad, Hercules, CA, USA). The purity of purified proteins was determined by SDS-PAGE, and the identity was confirmed by mass spectrometry (MS).

\section{SDS-PAGE}

Five microgram of each purified recombinant protein were reduced in a Tris buffer containing dithiothreitol ( $1 \% \mathrm{w} / \mathrm{v}$, Sigma), boiled for $5 \mathrm{~min}$, and loaded per well onto a $15 \%$ polyacrylamide gel before to be separated using a Mini PROTEAN II (BioRad, Hercules, CA, USA). After electrophoresis, gels were stained with
Coomassie brilliant blue R-250 (Imperial ${ }^{\mathrm{TM}}$ Protein Stain, Thermo Scientific, Rockford, IL, USA) and scanned with a high-resolution densitometer scanner (Image Scanner 3, GE Healthcare) and densitometry profiles were analysed using the ImageQuant ${ }^{\mathrm{TM}}$ TL software (GE Healthcare). Protein bands from gels were excised for further identification by mass spectrometry. Molecular weights were estimated by comparison with standard molecular weight marker (Biorad).

\section{In-gel digestion and mass spectrometry analysis}

Excised bands were digested overnight at $37^{\circ} \mathrm{C}$ with sequencing-grade trypsin $(12.5 \mu \mathrm{g} / \mathrm{mL}$; Promega Madison, WI, USA) in $50 \mathrm{mM} \mathrm{NH} \mathrm{HCO}_{3}$ (Sigma). The resulting peptides were extracted with $25 \mathrm{mM} \mathrm{NH}_{4} \mathrm{HCO}_{3}$ for 15 min, dehydrated with acetonitrile (ACN) (Sigma), incubated with $5 \%$ acid formic (Sigma) for 15 min under agitation, then dehydrated with ACN, and finally completely dried using a SpeedVac. The samples were then analysed on a NanoLC-LTQ-OrbitrapVelos-ETD (Thermo Scientific, Bremen, Germany) for identification.

\section{Enzyme-Linked ImmunoSorbent Assays (ELISA)}

ELISA was performed according to standard procedures. Microtiter 96-well plates (Nunc Maxisorp Immunoplates, Denmark) were coated for three hours at $37^{\circ} \mathrm{C}$ with $10 \mu \mathrm{g} /$ $\mathrm{ml}(50 \mu \mathrm{l} /$ well $)$ of either gSG6, g-5' nucleotidase, fSG6 and $\mathrm{f}-5^{\prime}$ nucleotidase purified recombinant anopheline proteins in $0.1 \mathrm{M}$ bicarbonate coating buffer ( $\mathrm{pH}$ 9.6) (Sigma). Three washes were done with $200 \mu \mathrm{L}$ of PBS (pH 7.4, Sigma, USA) plus $0.05 \%$ Tween-20 (Sigma) between each incubation. Plates were blocked overnight at $4^{\circ} \mathrm{C}$ with 200 $\mu \mathrm{L}$ of blocking buffer consisting of PBS $0.05 \%$ Tween and 5\% skimmed milk (Beckton, Dickinson Bioscience, USA). Serum diluted 1:50 in blocking buffer was added $(50 \mu \mathrm{l} /$ well) and incubated at $37^{\circ} \mathrm{C}$ for $1 \mathrm{~h}$. Fifty microliters of horseradish peroxidase (HRP)-conjugated rabbit antihuman IgG (1:10,000, Invitrogen, Rockville, USA) diluted in the blocking buffer were incubated for $1 \mathrm{~h}$ at $37^{\circ} \mathrm{C}$. Enzyme activity was detected by incubation with $50 \mu \mathrm{l}$ of tetramethylbenzidine substrate (KPL, USA) for $10 \mathrm{~min}$ at room temperature in the dark. The reaction was stopped using $50 \mu \mathrm{l}$ of $1 \mathrm{M} \mathrm{H}_{2} \mathrm{SO}_{4}$. The optical density (OD) at $450 \mathrm{~nm}$ was determined with a microplate reader (Versa Max $^{\circledR}$ Turnable Multiplate Reader, Molecular Devices, UK). Each serum was tested in duplicate against the different recombinant antigenic proteins and also without antigen (coating buffer only). In order to improve result consistencies, sera from different study sites have been randomly loaded on each plate and each individual serum were tested on the same plate against the four recombinant proteins. A pool of eight sera from individuals living in Dielmo and Ndiop sites presenting high level of antibody responses against the four anopheline recombinant 
proteins tested (selected based on ELISA optimisation tests), were used as a positive control on all plates coated. Only plates presenting inter-assay variations in absorbance values of positive controls lower than $20 \%$ were included in the analysis. The levels of IgG antibodies were expressed as adjusted OD (aOD), which was calculated for each serum sample duplicate as the mean OD value of antigenic proteins-coated wells minus the mean OD value of the background control wells (i.e., coating buffer without antigenic proteins). Sera whose duplicates showed a coefficient of variation $(\mathrm{CV}) \geq 20 \%$ were not included in the analysis. The mean aOD of unexposed individuals plus three standard deviation (SD) was used as cut-off value for seropositivity. Seroprevalence was defined as the pourcentage of seropositive individuals in each group.

\section{Protein sequence analysis}

Culicidae protein sequences that were related to the $5^{\prime}$ nucleotidases from both An. funestus (gi|114864746) and An. gambiae (gi|4582528) were retrieved from the National Center for Biotechnology Information (NCBI) using the BLASTp program. The hit sequences exhibiting a significant alignment (E-value $<1.10^{-4}$ ) and a hit sequence with coverage $\geq 70 \%$ and identity $\geq 50 \%$ were selected for further protein sequence comparisons. Multiple sequence alignment was performed with the Clustal W 1.7 multiple sequence alignment program [41], which is included in the Molecular Evolutionary genetic Analysis 5 (MEGA 5) programs package [42].

\section{Statistical analysis}

After verifying that values in each group did not assume a Gaussian distribution, the Kruskal-Wallis test was used for multiple group comparisons and the Friedman test was used to compare observations repeated on the same subjects in each study site. Two independent groups were compared by the Mann-Whitney U test. The Wilcoxon signed-rank test was used for comparison of two paired groups. Frequencies were compared by the Pearson's Chisquared test and Spearman's rank correlation coefficient was computed when appropriate. All differences were considered significant at $p<0.05$ and statistical analysis and figures were performed using the computing environment R (R Development Core Team, 2012).

\section{Results and discussion}

\section{Degree of conservation of salivary proteins}

Members of the $5^{\prime}$ nucleotidase/Apyrase family have been ubiquitously found in the saliva of hematophagous arthropods [19]. These enzymes are known to facilitate the acquisition of blood meals by removing and degrading pharmacologically active nucleotides (i.e., ATP/ADP) that are important for platelet aggregation at the site of the injury [43]. Three members of the 5 'nucleotidase gene family were described at the transcript level in $A n$. gambiae salivary glands [44]. Among them, the putative $5^{\prime}$ nucleotidase (gi|4582528) from An. gambiae (g-5'nuc) was highly expressed compared to the other two $5^{\prime}$ nucleotidase family members. The identification of the putative $5^{\prime}$ nucleotidase at the protein level in An. gambiae saliva $(64 \mathrm{kDa})$ confirmed that this salivary protein could be injected into the host during blood feeding [45]. Moreover, the induction of host antibody responses against members of the $5^{\prime}$ nucleotidase/Apyrase protein family has previously been reported [46-48]. Collectively, these data suggested that $5^{\prime}$ nucleotidase proteins could be used as potential immunological exposure markers to mosquito bites. To determine whether members from this protein family could be selected as antigenic candidates for the evaluation of exposure to mosquito bites at the species level, the degree of protein sequence diversity in the $5^{\prime}$ nucleotidase/Apyrase protein family among species from Culicidae was evaluated.

Among 5'nucleotidase anopheline proteins, the $5^{\prime}$ nucleotidase from An. funestus (f-5'nuc; gi|114864746) was selected based on its protein sequence peculiarities. Indeed, alignment of this sequence with the An. gambiae putative $5^{\prime}$ nucleotidase (g-5'nuc; gi $\mid 4582528$ ) indicated that the protein from $A n$. funestus lacks a large part of the amino-terminal domain (Additional file 1). The molecular weights and sizes (a.a. length) of $f-5^{\prime}$ nuc protein sequences (17 kDa, 139 a.a.) differ from those of g-5'nuc (64 kDa, 570 a.a.), which leads to a low coverage sequence $(31 \%)$ and a moderate identity $(<75 \%)$. When blasting the $\mathrm{f}-5^{\prime}$ nuc protein sequence (gi|114864746) against the Culicidae protein database on NCBInr $(\mathrm{NIH}$, Bethesda), 13 protein hits containing homologous sequences could be retrieved (E-value $<1.10^{-4}$, coverage $\geq 70 \%$ and identity $\geq 50 \%)$. An alignment of the $f-5^{\prime}$ nuc protein sequence (gi|114864746) with the members of the $5^{\prime}$ nucleotidase/Apyrase family from other Culicidae indicated that orthologous protein sequences from the Anopheles and Aedes genera presented amino-acid sequence similarities (Figure 1). Among these homologous proteins, two 5 'nucleotidase/Apyrase proteins from $A n$. gambiae (gi|4582528 and gi|58377530) and one from Anopheles stephensi (gi|27372911) presented amino-acid identities between 72-75\%, and the identity levels drop to less than $56 \%$ for all of the other selected proteins, suggesting an important diversity in this sequence among Culicidae. Interestingly, among all the sequences retrieved, only two members of the 5 'nucleotidase/Apyrase family (gi|208657657, gi|208657659) from the Anopheles darlingi species were also truncated at their aminoterminal end, but these proteins presented moderate identities $(<55 \%)$ with the 5 'nucleotidase from An. funestus. Thus, taken together, the $\mathrm{f}-5^{\prime}$ nuc protein peculiarities (i.e., a moderate level of sequence conservation within the 


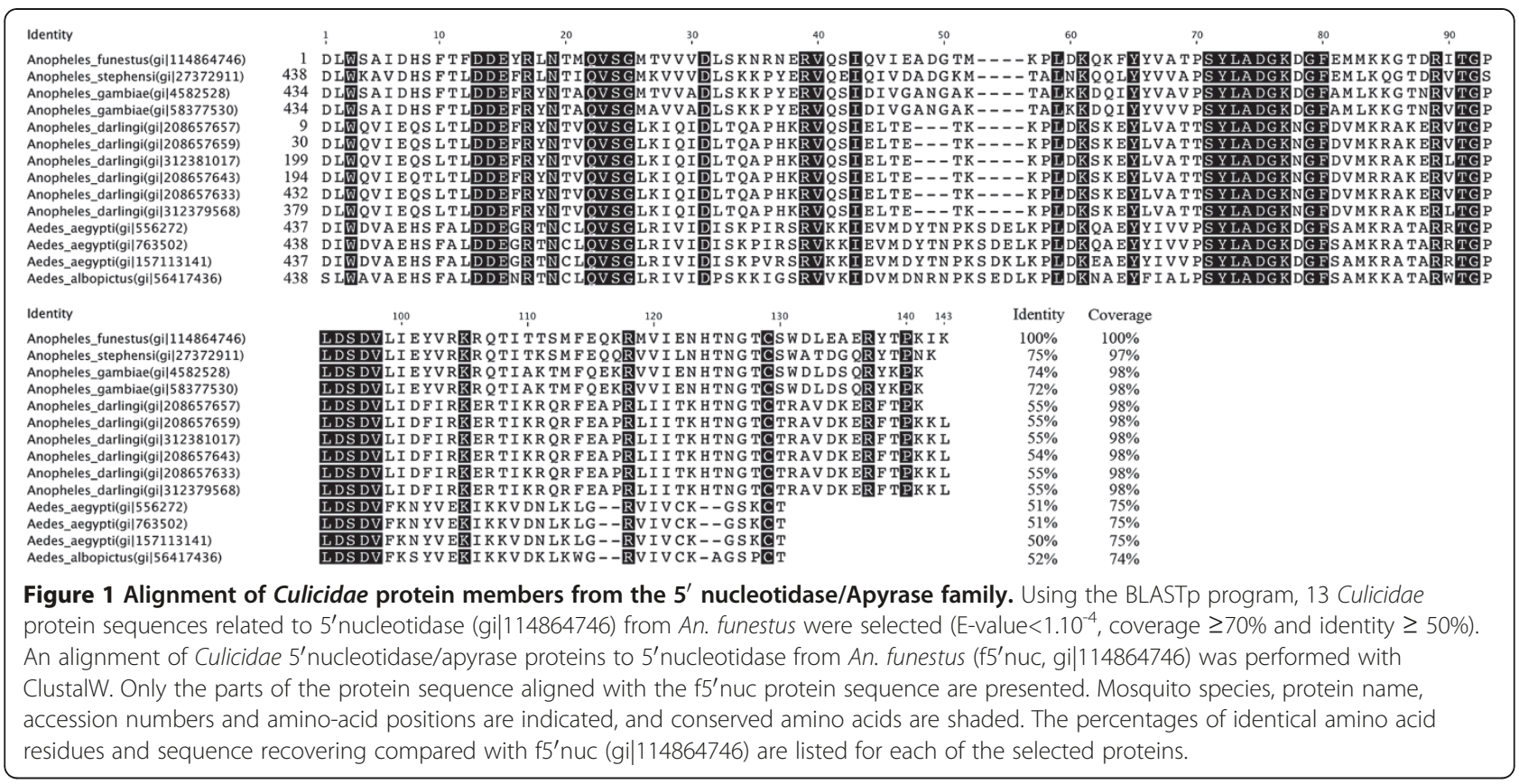

Culicidae family, an amino-terminal end truncation, the high abundance of these family proteins in the anopheline saliva and their involvement in eliciting host antibody responses) have highlighted our interest in assessing this protein as a potential marker candidate to distinguish exposure to An. funestus from exposure to An. gambiae s.l..

Concerning g5'nuc (gi|4582528), a sequence alignment showed that members of the 5 'nucleotidase/Apyrase family share only a moderate level of conservation of the protein sequences ( $<66 \%$ identical amino acids residues), with the exception of a paralogous protein from $A n$. gambiae (gi|58377530) and a salivary apyrase from $A n$. stephensi (gi|27372911) that possess $99 \%$ and $80 \%$ identical amino acid residues, respectively (Additional file 2 ). Due to their determinant role in blood feeding, these enzymes could be submitted to environmental pressures that lead to heterogeneous and independent sequence evolution.

SG6 proteins (gSG6, gi|13537666 and fSG6, gi| 114864550) were previously described to be restrictively present in the Cellia subgenus and are well conserved within this anopheline subgenus (Additional file 3) [21]. SG6 recombinant proteins were thus used as a reference immunological tool to evaluate the level of exposure to anopheline mosquitoes.

\section{Production of recombinant SG6 and 5'nucleotidase salivary orthologs from An. gambiae and An. funestus} A poly-histidine tag was added to the C-terminus of each recombinant protein to ensure the purification of whole recombinant proteins. gSG6 and g-5'nuc salivary proteins from An. gambiae, and fSG6 and f-5'nuc salivary proteins from An. funestus were produced in Sf9 cells using a baculovirus expression system and were purified by affinity chromatography (HisTrap HP) and a gel filtration column. The fractions corresponding to recombinant proteins were separated by SDS-PAGE, and a representative purified fraction for each protein is presented in Figure 2. As expected, protein bands with apparent molecular weights corresponding to gSG6 and fSG6 protein fractions were detected at approximately $13 \mathrm{kDa}$, and fractions corresponding to $\mathrm{g}-5^{\prime}$ nuc and $\mathrm{f}-5^{\prime}$ nuc were detected at approximately $65 \mathrm{kDa}$ and 17 $\mathrm{kDa}$, respectively. Proteins bands of interest were excised from the gel and submitted to mass spectrometry analysis, which confirmed that the detected bands corresponded to the expected recombinant proteins (Table 2). Protein profiles were analyzed using ImageQuant ${ }^{\mathrm{TM}} \mathrm{TL}$ software to determine the relative abundance of each purified recombinant protein as previously described $[49,50]$. The purity of the different recombinant proteins was greater than $90 \%$, and the protein fractions were considered sufficiently pure for ELISA experiments.

\section{IgG response against gSG6 and fSG6 proteins according} to anopheline populations and densities

Recently, Rizzo and collaborators evaluated the IgG responses in individuals living in a malaria hyperendemic area of Burkina Faso against recombinant gSG6 and fSG6 proteins from An. gambiae and An. funestus, respectively [26]. These individuals, exposed predominantly to An. gambiae s.l. bites, produced a comparable immune response against both SG6 salivary proteins, indicating a wide crossreactivity between these anopheline orthologous proteins. 


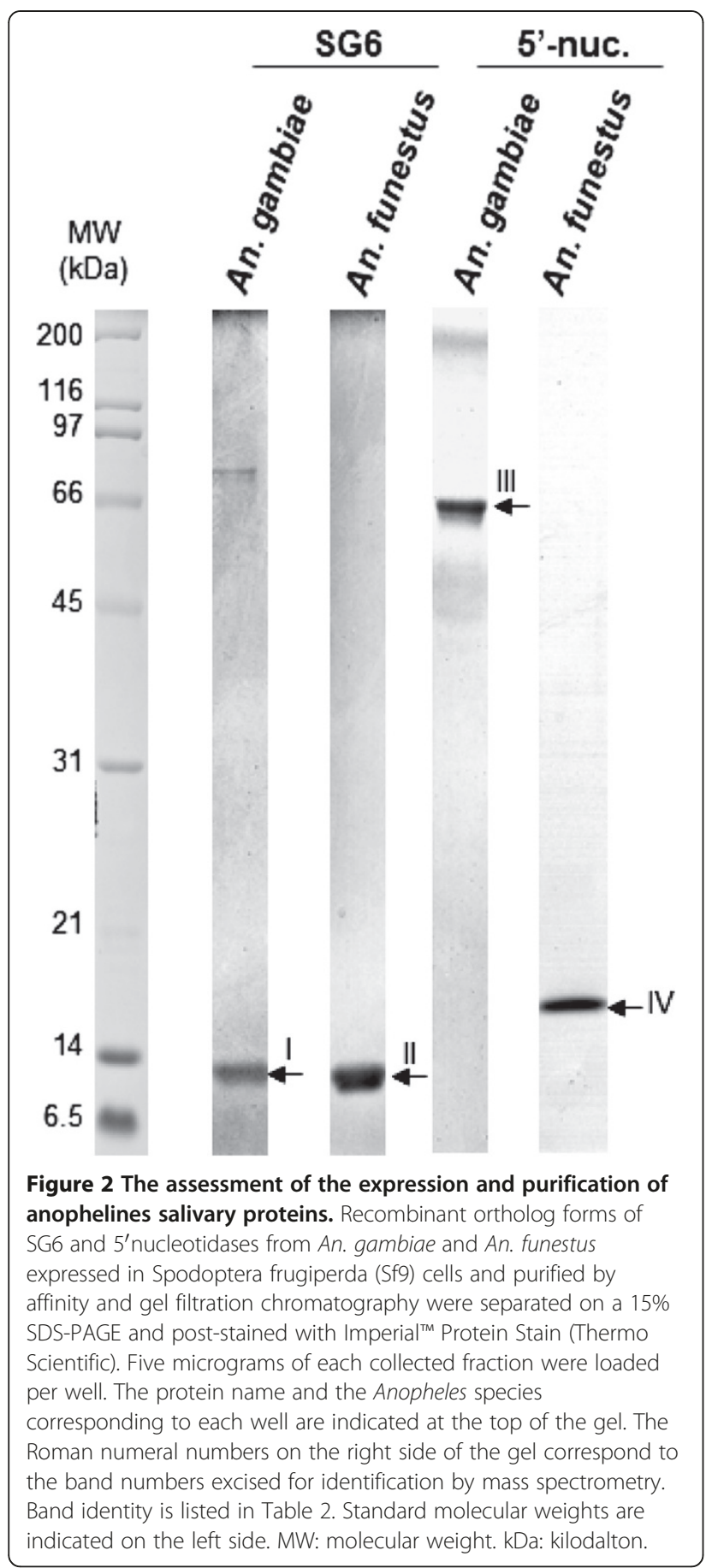

The high conservation of the gSG6 sequence between members of the An. gambiae species complex (greater than 99\%) and members of the Cellia subgenus, such as $A n$. funestus (with an identity of approximately $80 \%$ ), supports this idea of shared-antigens $[21,25,26]$. Based on these results, the gSG6 salivary protein was considered to be a valuable serological marker of exposure to Afrotropical malaria vectors.
However, Rizzo and collaborators did not evaluate the IgG responses against these two orthologous SG6 proteins in individuals exposed predominantly to An. funestus mosquito bites. To determine whether variations in the anopheline populations and densities could influence the IgG responses against recombinant orthologs of SG6 proteins from An. gambiae and An. funestus, the IgG responses against recombinant gSG6 and fSG6 proteins were assessed in our study in 134 individuals living in three Senegalese villages, Diama $(n=46)$, Ndiop $(n=50)$ and Dielmo $(\mathrm{n}=38)$ which are considered to be weakly (human biting rate $(\mathrm{HBR})<1)$ [37-39], moderately $(\mathrm{HBR}=$ $3.9)[35,36]$ and highly $(\mathrm{HBR}=30.6)$ exposed to Anopheles bites [34], respectively. These individuals were exposed to distinct anopheline populations, with a predominance of An. pharoensis (approximately 87\%) and An. gambiae s.l. mosquitoes (greater than 94\%) in Diama and NDiop, respectively, and a majority of An. funestus mosquitoes (66.4\%) in Dielmo (Table 1). Sera from European individuals $(n=45)$ living in Marseille, collected in February 2007 and never exposed to these tropical malaria vectors, were used as un-exposed controls. The IgG response against the gSG6 and fSG6 proteins was assessed by ELISA.

For gSG6 protein, the IgG responses were significantly different among the four groups (Kruskal-Wallis test, $p<0.0001$, Figure $3 \mathrm{~A}$ ). When comparisons were performed between two sites, the anti-gSG6 IgG responses were significantly higher in exposed individuals from each village (i.e., the means of aODs with a $95 \%$ confident interval $(95 \% \mathrm{CI})$ were +0.50 [0.39 to 0.60$],+0.65$ [0.53 to 0.76$]$ and +0.58 [0.49 to 0.66] for Diama, Dielmo and NDiop, respectively) compared with un-exposed control individuals $(+0.16$ [0.12 to 0.20]; Mann-Whitney $\mathrm{U}$ test, $p<0.0001)$. Conversely, despite distinct exposure levels to Anopheles bites in these three Senegalese villages, significant differences were detected only between Diama and Dielmo (Mann-Whitney U test, $p=0.0174$ ). Although the highest exposure to Anopheles bites was in Dielmo, followed by NDiop and finally Diama; the seroprevalence (a seropositivity cut-off was set as the mean aOD of un-exposed controls +3 SDs: $0.164+(3 \times 0.130)=0.554)$, with values of $55 \%, 52 \%$ and $37 \%$ in Dielmo, NDiop and Diama, respectively, was not found to be significantly different among the three villages (Pearson's Chi-squared test, $n s$, Figure 3C). These data support the hypothesis that gSG6 appears to be a valuable marker for distinguishing individuals who are un-exposed to anopheline bites from individuals who have been exposed to anopheline bites, and that this candidate is also well-adapted for the detection low levels of exposure to Anopheles bites [20,23]. Although the anti-gSG6 IgG response could discriminate exposed individuals from "low" to "high" Anopheles bite densities, such as in Diama and Dielmo, it seems to be less capable of distinguishing 
Table 2 Identification of recombinant salivary proteins by mass spectrometry

\begin{tabular}{|c|c|c|c|c|c|c|}
\hline Band number ${ }^{a}$ & $\begin{array}{l}\text { Accession number } \\
\text { (NCBi) }\end{array}$ & Protein Name & $\begin{array}{l}\text { Theoretical } M W \\
(k D a)\end{array}$ & $\begin{array}{l}\text { Number of MS/MS } \\
\text { peptide sequences }\end{array}$ & $\begin{array}{l}\text { Sequence } \\
\text { coverage (\%) }\end{array}$ & Mascot score \\
\hline I & gi|13537666 & $\begin{array}{l}\text { gSG6 protein } \\
\text { [An. gambiae] }\end{array}$ & 13.10 & 9 & 56.5 & 1929 \\
\hline$\|$ & gi|114864550 & $\begin{array}{l}\text { gSG6 salivary peptide } \\
\text { [An. funestus] }\end{array}$ & 13.06 & 4 & 25.4 & 205 \\
\hline III & gi|4582528 & $\begin{array}{l}\text { putative } 5^{\prime} \text {-nucleotidase } \\
\text { [An. gambiae] }\end{array}$ & 63.46 & 29 & 48.9 & 3703 \\
\hline IV & gi|114864746 & $\begin{array}{l}5^{\prime} \text { nucleotidase } \\
\text { [An. funestus] }\end{array}$ & 16.10 & 6 & 49.6 & 819 \\
\hline
\end{tabular}

\footnotetext{
${ }^{a}$ The band number corresponds to the same Roman numeral numbers as indicated in Figure 2.
}

The identities of the bands, their NCBi accession numbers, the theoretical molecular weight values, as well as the number of peptide sequences identified, the corresponding percentage sequence coverage and the Mascot score are listed for MS/MS analysis (Individual ions scores $>16$ indicate identity or extensive homology and were considered to be significant $(p<0.05)$.

"moderate" exposure, such as in NDiop, compared with high and low exposure sites. The individual heterogeneity of the IgG responses against gSG6 in each site could explain this powerless discrimination. This phenomenon could be attributed to the heterogeneity of Anopheles exposures according to distinct human behaviors or attractive differences, as recently described [51,52]. To better appreciate the variations of anti-gSG6 IgG levels, according to Anopheles densities, a kinetic analysis of the IgG response may be more appropriate and necessary.
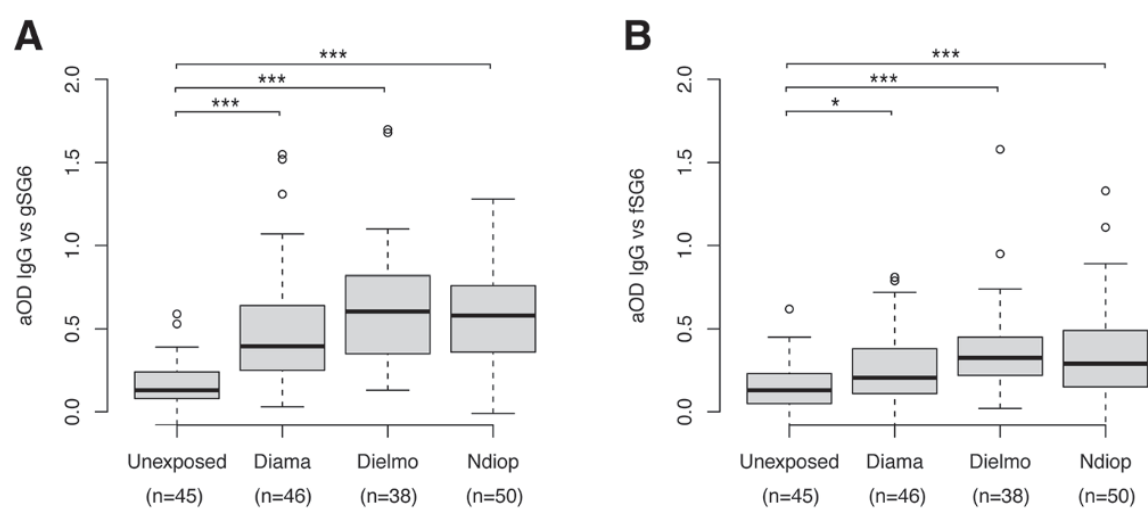

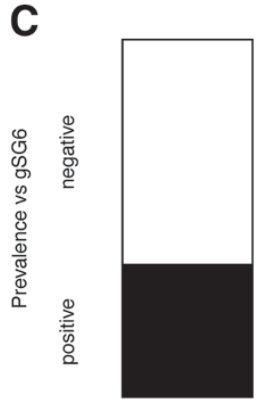

Diama

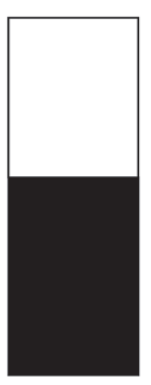

Dielmo

Study sites

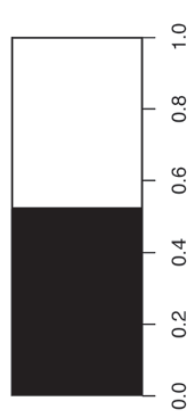

Ndiop
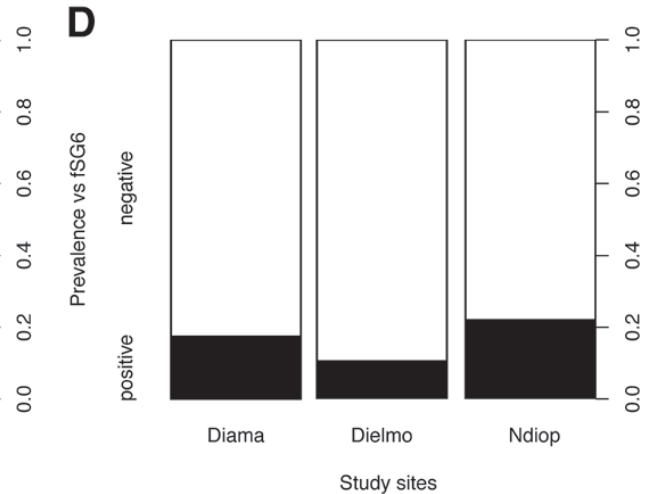

Figure 3 The IgG response and prevalence to gSG6 and fSG6 according to the level of mosquito bites and Anopheles populations (i.e., proportion of mosquito species). Box plots of aOD values from un-exposed $(n=45)$ and exposed (Diama, $n=46$; Dielmo, $n=38$ and Ndiop, $n=50$ ) individuals to gSG6 $(\mathbf{A})$ and fSG6 (B) proteins. Antibody responses are represented by aOD: the mean OD value of wells with recombinant salivary proteins minus the mean OD value of wells with coating buffer. The box plots display the median aOD value, 25 th and 75 th percentile. The whiskers indicate the 90th and 10th percentiles and the dots indicate the outliers. The P value was determined according to a Mann-Whitney $U$ test $\left(*, p<0.05 ;{ }^{* *}, p<0.01\right.$; $\left.{ }^{* * *}, p<0.001\right)$. The seroprevalence to gSG6 (C) and fSG6 (D) proteins in the four sites. The cut-off value for seropositivity (the mean aOD \pm 3 standard deviations) was defined at 0.55 for gSG6 and 0.59 for fSG6, based on the lgG reactivity of sera from individuals living in Marseille that were not previously exposed to An. gambiae s.l. and An. funestus. Individuals showing aOD values above the cut-off level for seropositivity were classified as responders. The whiskers denote the $95 \% \mathrm{Cl}$. The $\mathrm{P}$ values were determined by Pearson's Chi-squared test ( ${ }^{*}, p<0.05 ;{ }^{* *}, p<0.01$; $\left.^{* * *}, p<0.001\right)$. 
For the fSG6 protein, significantly different IgG responses were found among the four groups (Kruskal-Wallis test, $p<0.0001$, Figure 3B). These significant differences were attributed to higher IgG responses from exposed individuals living in Dielmo (i.e., a mean aOD [95\%CI] of + 0.38 [0.29 to 0.48], Mann-Whitney $\mathrm{U}$ test, $p<0.0001$ ), NDiop (i.e., + 0.35 [0.26 to 0.44], Mann-Whitney U test, $p<0.0004$ ) and Diama (i.e., +0.27 [0.19 to 0.34], MannWhitney $\mathrm{U}$ test, $p=0.0337$ ) compared with un-exposed control individuals (i.e., +0.15 [0.10 to 0.19$]$ ). As observed for gSG6, a comparison of the IgG responses between two Senegalese villages, indicated a significant difference only between Diama and Dielmo (Mann-Whitney $U$ test, $p=0.0194)$. The seroprevalence from Diama (17\%), Dielmo (11\%) and NDiop (22\%) (the seropositivity cut-off was set as the mean aOD of un-exposed controls + 3 SDs: $0.148+$ $(3 \times 0.146)=0.586)$ was not found to be significantly different among the three villages (Pearson's Chi-squared test, $p>0.05$, Figure 3D). As observed for gSG6, the anti-fSG6 IgG responses increased significantly in populations exposed to Anopheles bites, even in areas of low exposure; however, this method seems to be insufficiently sensitive to discern different gradients of Anopheles densities, and the immune response appears not to be perturbed by the anopheline fauna variations.

\section{Comparison of the IgG response between SG6 orthologs}

To estimate the cross-reactivity level of the IgG responses from exposed individuals of the three Senegalese villages ( $n=134$ ) against SG6 orthologs, a Spearman's rank correlation coefficient (rho) test was used, and the corresponding $p$-values were determined (Figure 4). A significant positive coefficient correlation $(\mathrm{r}=0.6208, p<0.0001)$ was observed between the IgG responses against g-SG6 and fSG6 among the exposed individuals. Despite the variations of Anopheles species proportion among the three villages, the large majority of individuals were "equivalently" distributed around the best-fit line. Thus, these observations strongly support a wide cross-reactivity to the gSG6 and fSG6 salivary antigens, which is in agreement with a previous study [26]. In agreement with Rizzo et al., the slope $(0.5923 \pm 0.0527)$ was greater than 0.45 , and the best-fit line runs below the diagonal [26]. This phenomenon resulted of in a higher IgG response level against gSG6 compared with fSG6 in the three villages, independent of the Anopheles population proportion. Interestingly, the IgG response against the fSG6 protein was significantly lower than that against gSG6, even in areas where individuals are predominantly exposed to An. funestus (Wilcoxon signed-rank test, $p<0.0001$, Additional file 4). These results suggest that, despite high sequence conservation among these orthologous SG6 proteins, fSG6 appears to be less antigenic than gSG6. The presence of few species-specific epitopes in each

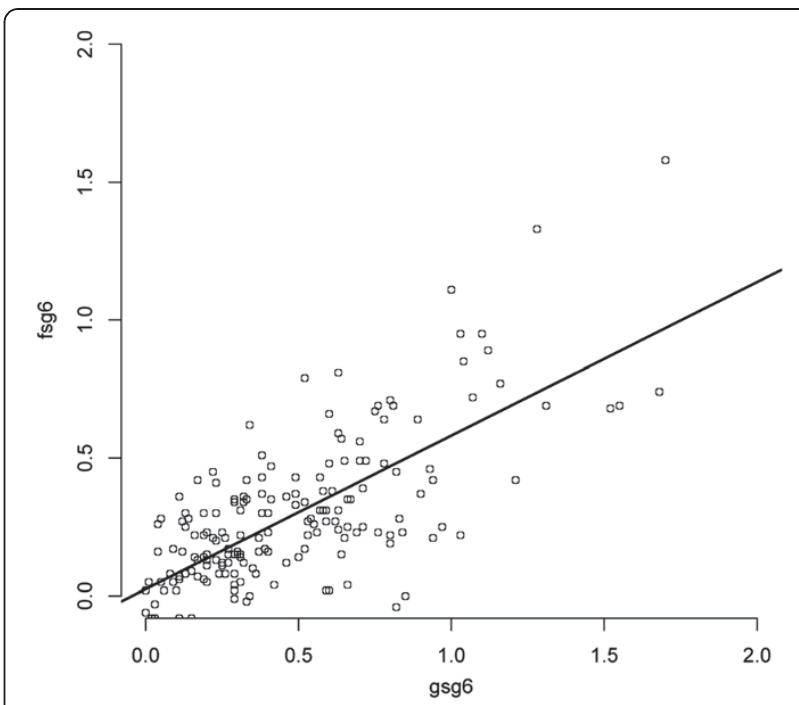

Figure 4 Correlation of IgG responses between SG6 ortholog recombinant proteins from two distinct Anopheles species. A scatter plot analysis of $\mathrm{lgG}$ response to gSG6 is presented, and the aOD values among the 134 exposed individual are reported. For gSG6 and fSG6 measurements, the best-fit is shown as a black line (slope $0.5923 \pm 0.0527$ ), with a Spearman's rank correlation coefficient (rho) of $r=0.6208, p<0.0001$.

SG6 protein could explain these differences in IgG responses [26].

Collectively, these data uphold that SG6 proteins could be specific markers of exposure to the Anopheles Celliasubgenus, and the use of these two proteins could improve the determination of the individual exposure level to these malaria vectors [26].

\section{IgG response against $\mathbf{g}-5^{\prime}$ nucleotidase and $\mathrm{f}$ - $5^{\prime}$ nucleotidase proteins according to anopheline populations and density}

The presence of numerous Anopheles species exhibiting differences in their biology and behavior and variations in mosquito species proportion and density throughout the seasons could have major implications for vector control programs $[53,54]$. Moreover, the geo-repartition and the density of the Anopheles species could vary from area to area in relatively close sites [55], which can increase the complexity of defining the precise regional malaria vectors responsible for malaria transmission. Thus, the achievement of species-specific individual exposure markers from major Afrotropical malaria vectors appears essential to evaluating the appropriateness of vector control measures and to identifying the Anopheles species considered to be the main malaria vector in any area at any given time point.

In addition to the SG6 Anopheline proteins, this study aimed to evaluate $\mathrm{f}-5^{\prime}$ nuc as a possible $A n$. funestus 
species-specific mosquito-bite-exposure marker. To assess the use of anti-f-5'nuc IgG responses as a tool to distinguish An. funestus exposure from An. gambiae s.l. exposure, the immune responses from individuals of the same Senegalese villages were evaluated by an ELISA against 5 'nucleotidase ortholog proteins from these two mosquito species.

For the g-5'nuc protein, the IgG responses were significantly different among the four groups (KruskalWallis test, $p<0.0001$, Figure 5A). When comparisons were performed between two sites, the anti-g-5'nuc IgG responses were significantly higher in exposed individuals from each village (i.e., the mean aODs [95\%CI] were +0.50 [0.40 to 0.61$],+0.51$ [0.39 to 0.63$]$ and +0.65 [0.52 to 0.77] for Diama, Dielmo and NDiop, respectively) compared with un-exposed control individuals $(i$. e., $+0.16[0.12$ to 0.21$]$; Mann-Whitney $U$ test, $p<0.0001)$. Conversely, no significant differences in the anti-g-5'nuc IgG responses was found, regardless of which two groups from these three Senegalese villages were being compared (Mann-Whitney U test, ns). Although a higher seroprevalence (the seropositivity cutoff was set as the mean aOD of un-exposed controls +3 SDs: $0.163+(3 \times 0.147)=0.604)$ was detected among individuals living in the NDiop area (40\%), where $A n$. gambiae s.l. is largely predominant, compared with Diama (28\%) and Dielmo (29\%), no significant differences were found among the three villages (Pearson's Chi-squared test, $n s$, Figure $5 \mathrm{C}$ ). These data suggest that the anti-g-5'nuc IgG responses could distinguish individuals un-exposed to Anopheles from individuals exposed to Anopheles, independent of the level of exposure or the anopheline fauna.

For the $f-5^{\prime}$ nuc protein, the IgG responses were significantly different among the four groups (Kruskal-Wallis test, $p<0.0001$, Figure $5 \mathrm{~B}$ ). In particular, the anti-f- $5^{\prime}$ nuc
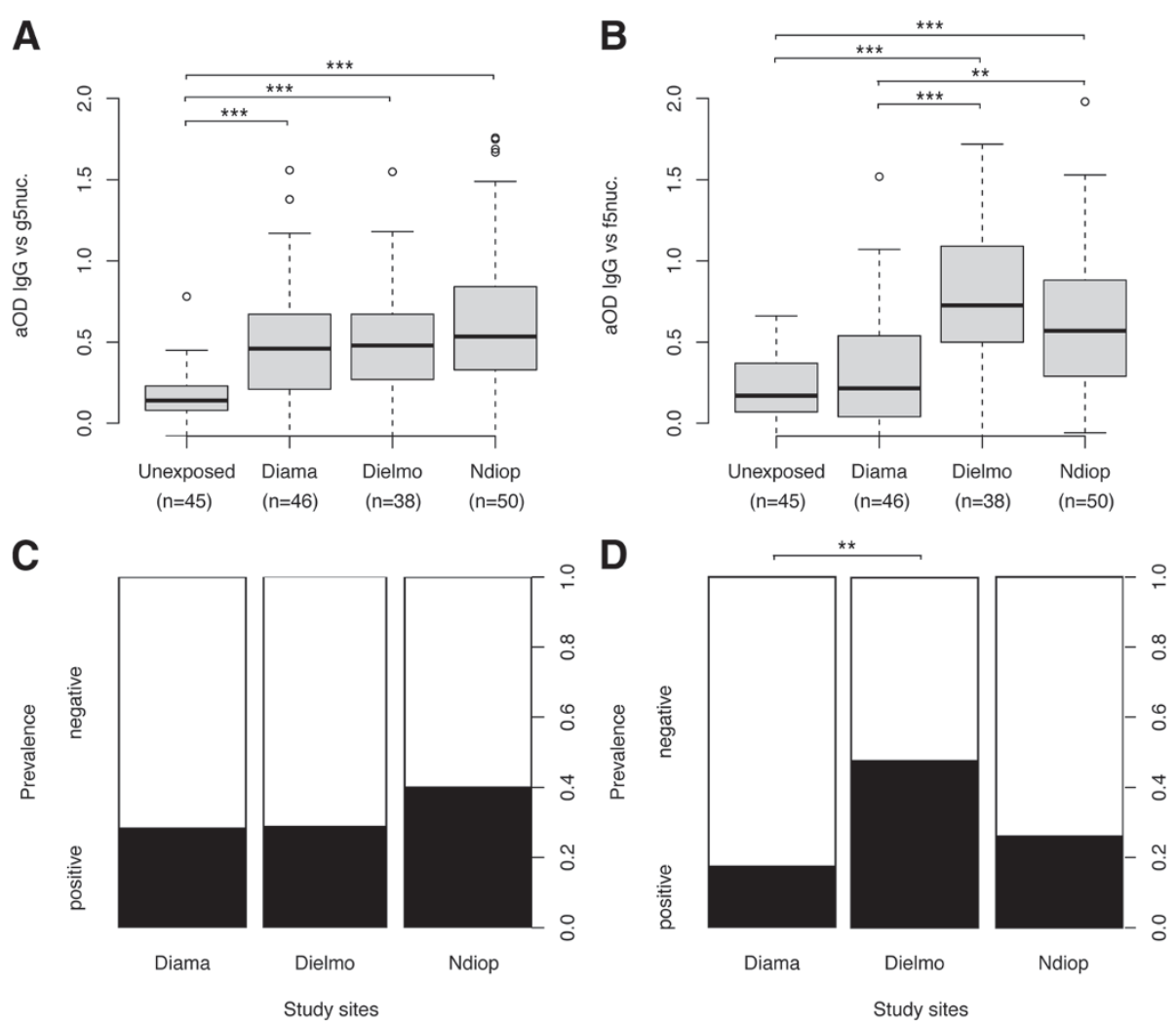

Figure 5 The lgG response and prevalence to $\mathrm{g}-5^{\prime}$ nuc and $\mathrm{f}-5^{\prime}$ nuc according to the level of mosquito bites and Anopheles populations (i.e., proportion of mosquito species). Box plots of aOD values from unexposed $(n=45)$ and exposed (Diama, $n=46 ;$ Dielmo, $n=38$ and Ndiop, $n=50$ ) individuals to $g-5^{\prime}$ nuc $(\mathbf{A})$ and $f-5^{\prime}$ nuc $(\mathbf{B})$ proteins. Antibody responses are represented by aOD: the mean OD value of wells with recombinant salivary proteins minus the mean OD value of wells with coating buffer. The box plots display the median aOD value, 25 th and 75 th percentile. The whiskers indicate the 90th and 10th percentiles and the dots indicate the outliers. The $P$ value was determined according to a Mann-Whitney $U$ test $\left({ }^{*}, p<0.05 ;{ }^{* *}, p<0.01\right.$; $\left.{ }^{* *}, p<0.001\right)$. The seroprevalence to $\mathrm{g}-5^{\prime}$ nuc $(\mathbf{C})$ and $\mathrm{f}-5^{\prime}$ nuc $(\mathbf{D})$ proteins in the four sites. The cut-

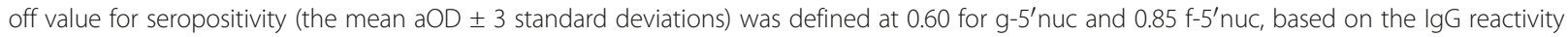
of sera from individuals living in Marseille that were not previously exposed to An. gambiae and An. funestus. Individuals showing aOD values above the cut-off level for seropositivity were classified as responders. The whiskers denote the $95 \% \mathrm{Cl}$. The $\mathrm{P}$ values were determined by Pearson's Chi-squared test ( ${ }^{*}, p<0.05 ;{ }^{* *}, p<0.01$; $\left.{ }^{* *}, p<0.001\right)$. 
IgG responses were significantly higher for exposed individuals living in Dielmo (i.e., +0.80 [0.65 to 0.96]) and NDiop (i.e., + 0.63 [0.50 to 0.76]), compared with unexposed control individuals (Mann-Whitney $U$ test, $p<0.0001$ for these two comparisons) or with individuals living in Diama (Mann-Whitney U test, $p<0.0001$ compared with Dielmo and $p<0.002$ compared with NDiop). No significant difference was noted between individuals living in Diama (i.e., a mean aOD [95\%CI] of $+0.34[0.22$ to 0.46$]$ ) and un-exposed control individuals (i.e., +0.22 [0.16 to 0.28]; Mann-Whitney U test, $n s$ ). The seroprevalence (the seropositivity cut-off was set as the mean aOD of un-exposed controls +3 SDs: $0.219+(3 \times 0.210)=$ 0.849 ) was found to be significantly different among individuals living in Dielmo (47\%) and those living in Diama (17\%) (Pearson's Chi-squared test, $p<0.007$, Figure 5D), corresponding to areas where An. funestus is predominantly present and absent, respectively. The seroprevalence of individuals living in NDiop (26\%) was not significantly different when compared with the two other Senegalese villages (Pearson's Chi-squared test, $n s$ ).

The absence of a significant anti-f- 5 'nuc IgG response among un-exposed individuals and among individuals living in Diama that were not exposed to An. funestus bites, in addition to the detection of highly significant differences in the anti-f- $5^{\prime}$ nuc IgG responses between individuals not exposed to An. funestus bites and individuals living in Dielmo or NDiop, suggests that exposure to $A n$. funestus bites seems to be required to elicit an antibody response against the $\mathrm{f}-5^{\prime}$ nuc protein. Indeed, the higher IgG response against $\mathrm{f}-5^{\prime}$ nuc that was detected at a site where $A n$. funestus is predominant is a supplementary argument supporting the idea that this salivary protein could reflect a species-specific exposure. Nevertheless, the data could not exclude the possibility that the anti-f-5'nuc IgG responses could correspond to the level of Anopheles bites. Indeed, the anopheline specimens collected in these three villages suggested a decreasing mosquito density gradient from Dielmo to Diama, with an intermediate exposure level in NDiop, which corresponds to the anti-f-5'nuc IgG pattern observed among these three areas. Comparisons of the anti-f-5'nuc IgG responses from individuals exposed uniquely to An. funestus or to An. gambiae s.l. at equivalent densities could dispel this ambiguity. Nevertheless, paired comparisons of the IgG responses against 5 'nuc orthologous proteins indicated a significant decrease and increase for individuals living in Diama (Wilcoxon signed-rank test, $p=0.023$ ) and Dielmo (Wilcoxon signed-rank test, $p=0.004$ ), respectively (Additional file 4).These data suggest that the recognition of these salivary proteins by the immune system was not equivalent and that specific antigenic epitopes may be associated with each protein.

\section{Comparison of the IgG response between $5^{\prime}$ nucleotidase orthologs}

To assess the cross-reactivity level of the IgG response of exposed individuals from the three Senegalese villages ( $\mathrm{n}=134$ ) against $5^{\prime}$ nuc orthologs, a Spearman's rank correlation coefficient (rho) test was used, and the corresponding $p$-values were determined. In contrast to the SG6 orthologs, no significant correlation was observed between the IgG responses from exposed individuals against g- $5^{\prime}$ nuc and $\mathrm{f}-5^{\prime}$ nuc recombinant proteins ( $\mathrm{r}=$ $0.1635, p=0.0591$ ). A high dispersion of the dots was visible on the scatter plot (Figure 6), underlining the fact that some individuals presented a larger response to either g-5'nuc or to $f-5^{\prime}$ nuc proteins. Thus, the antibody response against these $5^{\prime}$ nuc ortholog proteins indicated a low cross-reactivity, suggesting that, despite a partial conservation of the carboxy-terminal end of these proteins (74\% identical), the two proteins may be harboring "species"-specific epitopes. In addition, the large aminoterminal segment of g-5'nuc (i.e., from amino acid 1 to 434) could possibly possess antigenic sequences that are absent in $\mathrm{f}-5^{\prime}$ nuc and could explain the differences in serological recognition. Moreover, the g-5'nuc aminoterminal sequence possesses several cysteines $(n=7)$ that may be involved in protein folding, which could change the epitope conformation or mask some epitopes in the carboxy-terminal (which has partial homology with $\mathrm{f}-5^{\prime}$ nuc protein sequence). Indeed, the resulting cryptic epitopes in the g- $5^{\prime}$ nuc protein could be, in contrast, accessible to an antibody response in the $f-5^{\prime}$ nuc

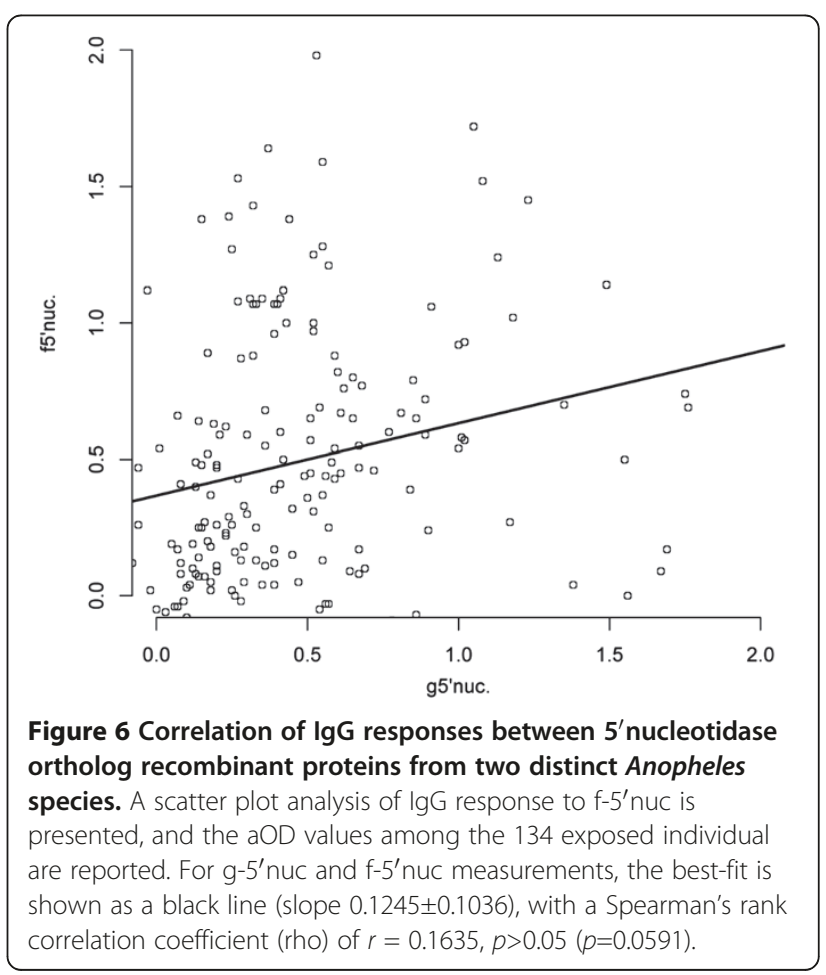


protein and, therefore, induce a "species"-specific serological response.

\section{Conclusion}

Understanding the complexity of the Anopheles species behavior is of major importance in vector control interventions to protect human populations against malaria. Anopheles gambiae s.l. and An. funestus share particularly anthropophilic tendencies that contribute to their vectorial capacity [56]. However, the existence of ecological and behavioral differences between these species have important epidemiological consequences [57]. Indeed, during the dry season, the densities of An. gambiae s.l. declined in some Sub-Saharan Africa areas, whereas the An. funestus abundance remained maximal, extending the period of malaria transmission. Therefore, the determination of human exposure to malaria vectors at the quantitative level (e.g., mosquito bite densities) and at the qualitative level (e.g., which mosquito species bite humans) should help to adapt malaria control strategies according to the spatial and temporal density of mosquito fauna [58].

To this end, the analysis of the human antibody response against mosquito salivary antigens has proved to be a relevant tool to assess host/vector contact $[16,17,59]$. As some areas can exhibit a high biodiversity in terms of mosquito species, a high level of specificity is necessary to assess individual exposure by immunological tests based on mosquito saliva. In addition, the presence of a diverse degree of salivary antigen cross-reactivity between different vector species demonstrates the need to precisely define antigenic candidate biomarkers to reflect exposure to several Anopheles species and to distinguish vector exposure at the species level [9].

Therefore, the production of specific mosquito saliva antigens in a recombinant form or by using synthetic peptides is a promising alternative strategy for producing safe and highly standardized antigens on a large scale $[21,24]$. A gain of specificity could be achieved by the use of synthetic peptides that do not share sequence homology with other hematophagous arthropod species [40]. However, the production of whole recombinant antigenic proteins could be more efficient to detect mosquito exposure [25].

The well-conservedSG6 protein family within the Anopheles Cellia subgenus made the SG6 proteins the first anopheline salivary candidates tested for the exploration of the relationship between levels of anti-gSG6 IgG responses and individual exposure to Anopheles bites. Encouraging data has accumulated for the use of the gSG6 salivary protein as serological marker of exposure to the Anopheles genus. Incontestably, the gSG6 protein can be used to detect exposure to Anopheles bites, even in areas of low exposure [23]. In the present study, the IgG response against SG6 from An. gambiae and An. funestus could distinguish individuals un-exposed to Anopheles bites from individuals exposed to Anopheles bites and could also distinguish high levels of exposures, independent of the anopheline Cellia species fauna. However, gSG6 was found to elicit a higher level of response than fSG6 orthologs. Overall, the analysis of IgG responses against SG6 ortholog proteins sustains the use of SG6 proteins as consistent indicators of exposure to three major malaria vectors in tropical Africa (i.e., $A n$. gamgiae, An. arabiensis and An. funestus).

In contrast, the presence of significantly different patterns and intensities of IgG responses against 5 'nucleotidase anopheline orthologs supports the idea that each of these proteins should possess specific antigenic epitopes. Moreover, the IgG response level against the $\mathrm{f}-5^{\prime}$ nuc protein seems to be associated with An. funestus densities. These initial tests provided encouraging preliminary information on the immunogenicity of the anopheline $5^{\prime}$ nuc proteins and present the promising possibility of using the 5 'nucleotidase salivary protein from An. funestus as the first species-specific antigenic marker of exposure. Complementary studies are needed to confirm the present assumption.

\section{Additional files}

Additional file 1: Paired-wise alignment of $5^{\prime}$-nucleotidase proteins
from An. gambiae and An.funestus.
Additional file 2: Comparison of sequence alignment of Culicidae
protein members from the $5^{\prime}$ nucleotidase/Apyrase family to
$5^{\prime}$-nucleotidase proteins from An. gambiae (gi|4582528).
Additional file 3: Phylogram tree constructed from the alignment
of the SG6 protein sequences from Anopheles species.
Additional file 4: Statistical analysis of variations in IgG responses
per site against the anopheline salivary proteins.

\section{Abbreviations}

ACN: Acetonitrile; aOD: adjusted optical density; Cl: Confident interval; CV: co-efficient of variation; ELISA: Enzyme-Linked ImmunoSorbent Assays; HBR: Human biting rate; MS: Mass spectrometry; NCBI: National Center for Biotechnology Information; SD: Standard deviation; SG6: Salivary gland protein 6.

\section{Competing interests}

The authors declare that they have no competing interests.

\section{Authors' contributions}

$A L$ and $R C$ conceived and designed the experiments. ZA and BM performed the experiments. AL, FA, RC, FC and PF analysed the data. BN, AS, BY, RF, VHV contributed reagents/materials/analysis tools. AL, FC, FA and RC wrote the paper. All authors read and approved the final manuscript.

\section{Acknowledgements}

The authors acknowledge S Bourdon, A Pascual and J Feuillard for its technical support, the Dr Gilles Riveau, DG de I'ONG EPLS (Espoir pour la Santé) de Saint-Louis du Sénégal for its participation in the human sera collection from individuals living in Diama. The authors also acknowledge all individuals for their participation. This study was supported by the French Armed Forces Medical Service and the Délégation Générale pour I'Armement (DGA, ArthroSER project, Grant PDH-2NRBC-5-B-101). 


\section{Author details}

${ }^{1} U$ nité de recherche en biologie et épidémiologie parasitaires (URBEP) UMR63 - IFR48, Institut de Recherche Biomédicale des Armées (Armed forces biomedical research institute, IRBA), antenne Marseille, GSBdD de Marseille Aubagne, 111 avenue de la corse, BP 40026, Marseille cedex 02 13568, France. ${ }^{2}$ Aix Marseille Université, Unité de Recherche en Maladies Infectieuses et Tropicales Emergentes (URMITE), UM63, CNRS 7278, IRD 198, Inserm 1095, WHO collaborative center for rickettsioses and other arthropod borne bacterial diseases, Faculté de Médecine, 27 bd Jean Moulin, Marseille cedex 5 13385, France. ${ }^{3}$ Marseille Proteomic (MaP), Centre de Recherche en Cancérologie de Marseille (CRCM), INSERM CNRS, Aix-Marseille Université, Institut Paoli-Calmette, 27, boulevard Leï Roure, BP 30059, Marseille cedex 09 13273, France. ${ }^{4}$ CNRS/CRBM, UMR5237, Montpellier F-34293, France. Institut de Recherche Biomédicale des Armées (IRBA), antenne Marseille, Unité d'Entomologie Médicale, URMITE UMR 6236, GSBdD de Marseille Aubagne, 111 avenue de la corse, BP 40026, Marseille cedex 02 13568, France. ${ }^{6}$ Cire Océan indien, 2bis avenue Georges Brassens, Saint Denis Cedex 9 CS 60050-97408, LA REUNION. ${ }^{7}$ Laboratoire Maladies Infectieuses et Vecteurs: Ecologie, Génétique, Evolution et Contrôle, UMR 224 CNRS/RDD/UM1, Montpellier, France. ${ }^{8}$ Institut Pasteur de Madagascar, Ambohitrakely, 101, B.P. 1274, Antananarivo, Madagascar.

Received: 22 October 2012 Accepted: 19 December 2012 Published: 31 December 2012

\section{References}

1. WHO: 2010. http://www.who.int.

2. Rogier C, Orlandi-Pradines E, Fusai T, Pradines B, Briolant S, Almeras L: [Malaria vaccines: prospects and reality]. Med Mal Infect 2006, 36:414-422.

3. Crompton PD, Pierce SK, Miller LH: Advances and challenges in malaria vaccine development. J Clin Invest 2010, 120:4168-4178.

4. Greenwood BM, Targett GA: Malaria vaccines and the new malaria agenda. Clin Microbiol Infect 2011, 17:1600-1607.

5. O'Brien C, Henrich PP, Passi N, Fidock DA: Recent clinical and molecular insights into emerging artemisinin resistance in Plasmodium falciparum. Curr Opin Infect Dis 2011, 24:570-577.

6. PPAV Working Groups: Personal protection against biting insects and ticks. Parasite 2011, 18:93-111.

7. Floore TG: Mosquito larval control practices: past and present. J Am Mosq Control Assoc 2006, 22:527-533.

8. Helinski ME, Parker AG, Knols BG: Radiation biology of mosquitoes. Malar J 2009, 8 Suppl 2:S6.

9. Fontaine A, Diouf I, Bakkali N, Misse D, Pages F, Fusai T, Rogier C, Almeras L: Implication of haematophagous arthropod salivary proteins in hostvector interactions. Parasit Vectors 2011, 4:187.

10. Killeen GF, McKenzie FE, Foy BD, Schieffelin C, Billingsley PF, Beier JC: The potential impact of integrated malaria transmission control on entomologic inoculation rate in highly endemic areas. Am J Trop Med Hyg 2000, 62:545-551.

11. Pennetier C, Corbel V, Boko P, Odjo A, N'Guessan R, Lapied B, Hougard JM: Synergy between repellents and non-pyrethroid insecticides strongly extends the efficacy of treated nets against Anopheles gambiae. Malar $J$ 2007, 6:38.

12. Ribeiro JM: Blood-feeding arthropods: live syringes or invertebrate pharmacologists? Infect Agents Dis 1995, 4:143-152.

13. Peng Z, Estelle F, Simons R: Mosquito allergy and mosquito salivary allergens. Protein Pept Lett 2007, 14:975-981.

14. Waitayakul A, Somsri S, Sattabongkot J, Looareesuwan S, Cui L, Udomsangpetch R: Natural human humoral response to salivary gland proteins of Anopheles mosquitoes in Thailand. Acta Trop 2006, 98:66-73.

15. Remoue F, Cisse B, Ba F, Sokhna C, Herve JP, Boulanger D, Simondon F: Evaluation of the antibody response to Anopheles salivary antigens as a potential marker of risk of malaria. Trans R Soc Trop Med Hyg 2006, 100:363-370.

16. Fontaine A, Pascual A, Orlandi-Pradines E, Diouf I, Remoue F, Pages F, Fusai T, Rogier C, Almeras L: Relationship between exposure to vector bites and antibody responses to mosquito salivary gland extracts. PLoS One 2011, 6:e29107.

17. Orlandi-Pradines E, Almeras $L$, Denis de Senneville L, Barbe $S$, Remoue F, Villard C, Cornelie S, Penhoat K, Pascual A, Bourgouin C, et al: Antibody response against saliva antigens of Anopheles gambiae and Aedes aegypti in travellers in tropical Africa. Microbes Infect 2007, 9:1454-1462.

18. Drame PM, Poinsignon A, Besnard P, Le Mire J, Dos-Santos MA, Sow CS, Cornelie S, Foumane V, Toto JC, Sembene M, et al: Human antibody response to Anopheles gambiae saliva: an immuno-epidemiological biomarker to evaluate the efficacy of insecticide-treated nets in malaria vector control. Am J Trop Med Hyg 2010, 83:115-121.

19. Ribeiro JM, Mans BJ, Arca B: An insight into the sialome of blood-feeding Nematocera. Insect Biochem Mol Biol 2010, 40:767-784.

20. Poinsignon A, Cornelie S, Mestres-Simon M, Lanfrancotti A, Rossignol M, Boulanger D, Cisse B, Sokhna C, Arca B, Simondon F, Remoue F: Novel peptide marker corresponding to salivary protein gSG6 potentially identifies exposure to Anopheles bites. PLoS One 2008, 3:e2472.

21. Lombardo F, Ronca R, Rizzo C, Mestres-Simon M, Lanfrancotti A, Curra C, Fiorentino G, Bourgouin C, Ribeiro JM, Petrarca V, et al: The Anopheles gambiae salivary protein gSG6: an anopheline-specific protein with a blood-feeding role. Insect Biochem Mol Biol 2009, 39:457-466.

22. Badu K, Siangla J, Larbi J, Lawson BW, Afrane Y, Ong'echa M, Remoue F, Zhou G, Githeko AK, Yan G: Variation in exposure to Anopheles gambiae salivary gland peptide (gSG6-P1) across different malaria transmission settings in the western Kenya highlands. Malar J 2012, 11:318.

23. Poinsignon A, Cornelie S, Ba F, Boulanger D, Sow C, Rossignol M, Sokhna C, Cisse $B$, Simondon F, Remoue F: Human IgG response to a salivary peptide, gSG6-P1, as a new immuno-epidemiological tool for evaluating low-level exposure to Anopheles bites. Malar J 2009, 8:198.

24. Poinsignon A, Samb B, Doucoure S, Drame PM, Sarr JB, Sow C, Cornelie S, Maiga S, Thiam C, Rogerie F, et al: First attempt to validate the gSG6-P1 salivary peptide as an immuno-epidemiological tool for evaluating human exposure to Anopheles funestus bites. Trop Med Int Health 2010, 15:1198-1203.

25. Rizzo C, Ronca R, Fiorentino G, Verra F, Mangano V, Poinsignon A, Sirima SB, Nebie I, Lombardo F, Remoue F, et al: Humoral response to the Anopheles gambiae salivary protein gSG6: a serological indicator of exposure to Afrotropical malaria vectors. PLoS One 2011, 6:e17980.

26. Rizzo C, Ronca R, Fiorentino G, Mangano VD, Sirima SB, Nebie I, Petrarca V, Modiano D, Arca B: Wide cross-reactivity between Anopheles gambiae and Anopheles funestus SG6 salivary proteins supports exploitation of gSG6 as a marker of human exposure to major malaria vectors in tropical Africa. Malar J 2011, 10:206.

27. Stone W, Bousema T, Jones S, Gesase S, Hashim R, Gosling R, Carneiro I, Chandramohan D, Theander T, Ronca R, et al: IgG responses to Anopheles gambiae salivary antigen gSG6 detect variation in exposure to malaria vectors and disease risk. PLoS One 2012, 7:e40170.

28. Sinka ME, Bangs MJ, Manguin S, Coetzee M, Mbogo CM, Hemingway J, Patil AP, Temperley WH, Gething PW, Kabaria CW, et al: The dominant Anopheles vectors of human malaria in Africa, Europe and the Middle East: occurrence data, distribution maps and bionomic precis. Parasit Vectors 2010, 3:117.

29. Muturi EJ, Shililu JI, Jacob BG, Mwangangi JM, Mbogo CM, Githure Jl, Novak RJ: Diversity of riceland mosquitoes and factors affecting their occurrence and distribution in Mwea, Kenya. J Am Mosq Control Assoc 2008, 24:349-358.

30. Manguin S, Garros C, Dusfour I, Harbach RE, Coosemans M: Bionomics, taxonomy, and distribution of the major malaria vector taxa of Anopheles subgenus Cellia in Southeast Asia: an updated review. Infect Genet Evol 2008, 8:489-503.

31. Sinka ME, Bangs MJ, Manguin S, Chareonviriyaphap T, Patil AP, Temperley WH, Gething PW, Elyazar IR, Kabaria CW, Harbach RE, Hay SI: The dominant Anopheles vectors of human malaria in the Asia-Pacific region: occurrence data, distribution maps and bionomic precis. Parasit Vectors 2011, 4:89.

32. Trung HD, Bortel W, Sochantha T, Keokenchanh K, Briet OJ, Coosemans M: Behavioural heterogeneity of Anopheles species in ecologically different localities in Southeast Asia: a challenge for vector control. Trop Med Int Health 2005, 10:251-262.

33. Adja AM, N'Goran EK, Koudou BG, Dia I, Kengne P, Fontenille D, Chandre F: Contribution of Anopheles funestus, An. gambiae and An. nili (Diptera: Culicidae) to the perennial malaria transmission in the southern and western forest areas of Cote d'Ivoire. Ann Trop Med Parasitol 2011, 105:13-24.

34. Fontenille D, Lochouarn L, Diagne N, Sokhna C, Lemasson JJ, Diatta M, Konate L, Faye F, Rogier C, Trape JF: High annual and seasonal variations 
in malaria transmission by anophelines and vector species composition in Dielmo, a holoendemic area in Senegal. Am J Trop Med Hyg 1997, 56:247-253

35. Fontenille D, Lochouarn L, Diatta M, Sokhna C, Dia I, Diagne N, Lemasson JJ, Ba K, Tall A, Rogier C, Trape JF: Four years' entomological study of the transmission of seasonal malaria in Senegal and the bionomics of Anopheles gambiae and A. arabiensis. Trans R Soc Trop Med Hyg 1997, 91:647-652.

36. Sokhna CS, Diagne N, Lochouarn L, Rogier C, Trape JF, Spiegel A, Fontenille D: [Comparative evaluation of the plasmodial infection of Anopheles using ELISA and dissection. Consequences for the estimation of the transmission of malaria in 1995 in Ndiop, Senegal]. Parasite 1998, 5:273-279.

37. Faye $\mathrm{O}$, Gaye $\mathrm{O}$, Konate L, Molez JF, Feller-Dansokho E, Herve JP: [Prediction and prevention of malaria epidemics in the valley of the Senegal River]. Sante 1998, 8:347-352.

38. Faye O, Fontenille D, Gaye O, Sy N, Molez JF, Konate L, Hebrard G, Herve JP, Trouillet J, Diallo $S$, et al: [Malaria and rice growing in the Senegal River delta (Senegal)]. Ann Soc Belg Med Trop 1995, 75:179-189.

39. Sow S, de Vlas SJ, Engels D, Gryseels B: Water-related disease patterns before and after the construction of the Diama dam in northern Senegal. Ann Trop Med Parasitol 2002, 96:575-586.

40. Ambrosino E, Dumoulin C, Orlandi-Pradines E, Remoue F, Toure-Balde A, Tall A, Sarr JB, Poinsignon A, Sokhna C, Puget K, et al: A multiplex assay for the simultaneous detection of antibodies against 15 Plasmodium falciparum and Anopheles gambiae saliva antigens. Malar J 2010, 9:317.

41. Thompson JD, Higgins DG, Gibson TJ: CLUSTAL W: improving the sensitivity of progressive multiple sequence alignment through sequence weighting, position-specific gap penalties and weight matrix choice. Nucleic Acids Res 1994, 22:4673-4680.

42. Tamura K, Peterson D, Peterson N, Stecher G, Nei M, Kumar S: MEGA5: molecular evolutionary genetics analysis using maximum likelihood, evolutionary distance, and maximum parsimony methods. Mol Biol Evol 2011, 28:2731-2739.

43. Ribeiro JM, Francischetti IM: Role of arthropod saliva in blood feeding: sialome and post-sialome perspectives. Annu Rev Entomol 2003, 48:73-88.

44. Das S, Radtke A, Choi YJ, Mendes AM, Valenzuela JG, Dimopoulos G: Transcriptomic and functional analysis of the Anopheles gambiae salivary gland in relation to blood feeding. BMC Genomics 2010, 11:566.

45. Choumet V, Carmi-Leroy A, Laurent C, Lenormand P, Rousselle JC, Namane A, Roth C, Brey PT: The salivary glands and saliva of Anopheles gambiae as an essential step in the Plasmodium life cycle: a global proteomic study. Proteomics 2007, 7:3384-3394.

46. Xu W, Simons FE, Peng Z: Expression and rapid purification of an Aedes aegypti salivary allergen by a baculovirus system. Int Arch Allergy Immunol 1998, 115:245-251.

47. Peng Z, Xu W, James AA, Lam H, Sun D, Cheng L, Simons FE: Expression, purification, characterization and clinical relevance of rAed a 1-a $68-\mathrm{kDa}$ recombinant mosquito Aedes aegypti salivary allergen. Int Immunol 2001, 13:1445-1452

48. Peng Z, Simons FE: Advances in mosquito allergy. Curr Opin Allergy Clin Immunol 2007, 7:350-354.

49. Almeras L, Fontaine A, Belghazi M, Bourdon S, Boucomont-Chapeaublanc E, Orlandi-Pradines E, Baragatti M, Corre-Catelin N, Reiter P, Pradines B, et al: Salivary gland protein repertoire from Aedes aegypti mosquitoes. Vector Borne Zoonotic Dis 2010, 10:391-402.

50. Almeras L, Orlandi-Pradines E, Fontaine A, Villard C, Boucomont E, de Senneville LD, Baragatti M, Pascual A, Pradines B, Corre-Catelin N, et al: Sialome individuality between Aedes aegypti colonies. Vector Borne Zoonotic Dis 2009, 9:531-541.

51. Drame PM, Machault V, Diallo A, Cornelie S, Poinsignon A, Lalou R, Sembene M, Dos Santos S, Rogier C, Pages F, et al: IgG responses to the gSG6-P1 salivary peptide for evaluating human exposure to Anopheles bites in urban areas of Dakar region, Senegal. Malar J 2012, 11:72.

52. Qiu YT, Smallegange RC, Van Loon JJ, Ter Braak CJ, Takken W: Interindividual variation in the attractiveness of human odours to the malaria mosquito Anopheles gambiae s. s. Med Vet Entomol 2006, 20:280-287

53. Cottrell G, Kouwaye B, Pierrat C, le Port A, Bouraima A, Fonton N, Hounkonnou MN, Massougbodji A, Corbel V, Garcia A: Modeling the influence of local environmental factors on malaria transmission in Benin and its implications for cohort study. PLoS One 2012, 7:e28812.

54. Meyrowitsch DW, Pedersen EM, Alifrangis M, Scheike TH, Malecela MN, Magesa SM, Derua YA, Rwegoshora RT, Michael E, Simonsen PE: Is the current decline in malaria burden in sub-Saharan Africa due to a decrease in vector population? Malar J 2011, 10:188.

55. Atangana J, Bigoga JD, Patchoke S, Ndjemai MN, Tabue RN, Nem TE, Fondjo E: Anopheline fauna and malaria transmission in four ecologically distinct zones in Cameroon. Acta Trop 2010, 115:131-136.

56. Mbogo CM, Mwangangi JM, Nzovu J, Gu W, Yan G, Gunter JT, Swalm C, Keating J, Regens JL, Shililu Jl, et al: Spatial and temporal heterogeneity of Anopheles mosquitoes and Plasmodium falciparum transmission along the Kenyan coast. Am J Trop Med Hyg 2003, 68:734-742.

57. Kelly-Hope LA, Hemingway J, McKenzie FE: Environmental factors associated with the malaria vectors Anopheles gambiae and Anopheles funestus in Kenya. Malar J 2009, 8:268.

58. Coetzee M, Fontenille D: Advances in the study of Anopheles funestus, a major vector of malaria in Africa. Insect Biochem Mol Biol 2004, 34:599-605.

59. Cornelie S, Remoue F, Doucoure S, Ndiaye T, Sauvage FX, Boulanger D, Simondon F: An insight into immunogenic salivary proteins of Anopheles gambiae in African children. Malar J 2007, 6:75.

doi:10.1186/1475-2875-11-439

Cite this article as: Ali et al:: Assessment of Anopheles salivary antigens as individual exposure biomarkers to species-specific malaria vector bites. Malaria Journal 2012 11:439.

\section{Submit your next manuscript to BioMed Central and take full advantage of:}

- Convenient online submission

- Thorough peer review

- No space constraints or color figure charges

- Immediate publication on acceptance

- Inclusion in PubMed, CAS, Scopus and Google Scholar

- Research which is freely available for redistribution 